\title{
Pulp Therapies in Young Permanent Maxillary Molar With Class I Caries
}

Research Article

\section{S.S.Shivanni ${ }^{1}$, Bhagya Lakshmi $\mathrm{T}^{2 *}$, Balakrishna $\mathrm{RN}^{3}$}

${ }^{1}$ Saveetha Dental College and Hospitals, Saveetha Institute of Medical and Technical Sciences, Saveetha University, Chennai, India.

${ }^{2}$ Senior Lecturer, Department of Pediatric and Preventive Dentistry Saveetha Dental College and Hospitals, Saveetha Institute of Medical and Technical Sciences, Saveetha University, Chennai, India.

${ }^{3}$ Senior Lecturer, Department of Oral and maxillofacial surgery, Saveetha Dental College and Hospitals, Saveetha Institute of Medical and Technical Sciences, Saveetha University, Chennai 600077, India.

\section{Abstract}

The aim of this study is to assess the prevalence of pulp therapies in young permanent maxillary molars with occlusal caries. Exposure of pulp due to various reasons results in inflammation of the pulp which can lead to pulpal necrosis if left untreated. The study includes patients visiting the OP of University in Chennai who are diagnosed with Class I caries in the young permanent maxillary molars. The number of pulp therapy procedures done among the study population were assessed and the results were statistically analysed and graphs were tabulated. Among the total patients, It was found that a significantly high frequency $(94.6 \%)$ of pulp therapy procedures were pulpectomies; and $58.1 \%$ of cases were done in the left maxillary first molar. This study shows that pulpectomy was highly performed over pulpotomy, although many researches state that pulpotomy is preferred for immature permanent teeth. This may be due to the extent of caries.

Keywords: Pulp Therapies; Occlusal Caries; Young Permanent Maxillary Molars.

\section{Introduction}

The dental pulp is a soft connective tissue confined within the hard walls of the dentin which plays an important role in the prognosis of the tooth,which is often ignored. Exposure of pulp due to various reasons results in inflammation of the pulp which can lead to pulpal necrosis if left untreated [1]. Therapeutics of dental pulp diseases include direct and indirect pulp capping, Pulpotomy and pulpectomy. Preservation of pulp vitality is important as it serves several functions like dentin formation, nutrition, reparative capacity etc. Hence, preserving the pulp vitality is better than to replace it with a root canal filling material [2].

The main objective of pulp therapy in the primary dentition is to retain every primary tooth as a fully functional component in the dental arch to allow for proper mastication, phonation, swallowing, preservation of the space required for eruption of permanent teeth and prevention of detrimental psychological effects due to tooth loss [3].
Pulpotomy is a procedure in which the coronal portion of the pulp is removed surgically and the remaining radical arms pulp is retained. A pulp protecting agent is placed to prevent further damage to the pulp [4]. The rationale behind pulpotomy is based on the ability of remaining radicals to recover following the removal of infected coronal pulp and placement of medicaments [5].

Pulpectomy is a conservative treatment approach in preventing the premature loss of the tooth [6]. An appropriate pulpectomy of the teeth rather than extraction is a reasonable treatment option to ensure long term survival [7]. The primary objective of pulp treatment is to maintain the integrity and health of the oral tissues. Although a tooth can remain functional without a pulp,it is desirable to attempt to maintain the vitality of the pulp [8].

Indirect pulp capping is the procedure in which a small amount of carious dentin is retained in deep areas of cavity preparation

\section{*Corresponding Author:}

Dr. Bhagya Lakshmi T,

Senior Lecturer, Department of Pediatric and Preventive Dentistry, Saveetha Dental College, Saveetha Institute of Medical and Technical Sciences, Saveetha University, 162, PH Road, Chennai 600077, Tamil Nadu, India.

Tel: +919642432345

E-mail: bhagyalakshmit.sdc@saveetha.com

Received: October 28, 2019

Accepted: November 24, 2019

Published: November 282019

Citation: S.S.Shivanni, Bhagya Lakshmi T, Balakrishna RN. Pulp Therapies in Young Permanent Maxillary Molar With Class I Caries. Int J Dentistry Oral Sci. 2019;:57:02:001:1-4. doi: http://dx.doi.org/10.19070/2377-8075-SI02-07001

Copyright: Bhagya Lakshmi $\mathbf{T}^{\circ} 2019$. This is an open-access article distributed under the terms of the Creative Commons Attribution License, which permits unrestricted use, distribution and reproduction in any medium, provided the original author and source are credited. 
to avoid an exposure of the pulp. A medicament is then placed over the carious dentin to stimulate and encourage pulp recovery. Indirect pulp therapy performed in primary and permanent teeth of young patients may result in a high 3-year survival rate. Direct pulp capping is defined as the placement of a medicament on a pulp that has been exposed during excavation of deep dental caries. The rationale behind this treatment is to encourage young healthy pulps to initiate a dentin bridge [9].

It is frequently maintained that pulp capping and pulpotomy procedures should be considered for minimally affected teeth [9-11]. The advantages of preserving the pulp is obvious in cases with large pulp chambers and underdeveloped roots because pulpectomy arrested root development [11-13]. The most radical approach is to remove the entire pulp and replace it with a root canal filling material $[13,14]$. Vital pulp therapy is indicated for pulp exposure in teeth with incompletely formed roots, but once root formation has been completed, pulpectomy or root canal therapy should be performed [15].

Previously our team had conducted numerous clinical trials [2123, 25-27, 29, 35], and epidemiological surveys [24, 28] over the past 5 years. The idea for this retrospective study was stemmed from the current interest in our community. The aim of this study is to assess the prevalence of pulp therapies done in young permanent maxillary molars with occlusal caries among patients aged between 6-11 years attending the OP of the department of Pedodontics at the University in Chennai.

\section{Materials and Methods}

A retrospective study was carried out in patients between the age of 6-11 years who visited University in Chennai who have undergone pulp therapy in young permanent maxillary molars. Data from 1st June 2018 to 30th March 2019 was collected from patient records which includes details of patients, intraoral photographs and treatment being done. Inclusion criteria:Patients between the age of 6-11 years, both males and females are included, patients with occlusal caries (Class I) on young permanent maxillary molars. Exclusion criteria:Tooth with caries on surfaces other than the occlusal surface.

Sample size $[\mathrm{N}=74]$ is the total number of patients who visited University in Chennai with occlusal caries on young permanent maxillary molars and underwent pulp therapy. Sample distribution according to age, gender and teeth number were recorded.

Ethical clearance was obtained from the Institutional Ethical Committee and Scientific Review Board [SRB] of University in Chennai.

The data collected was entered in an Excel sheet and subjected to statistical analyses using SPSS software. Descriptive statistics were done i.e frequency and cross tabulation. A chi square test was done between age and tooth affected. Independent variables are age and gender, while dependent variables are teeth number and surface affected. The level of significance was $\mathrm{p}<0.05$.

\section{Results and Discussion}

A total of 74 patients were seen during the study period. The most predominant pulp therapy procedure done was found to be the pulpectomy with a percentage of $94.6 \%$. Pulpotomy on the other hand was only found to be $5.4 \%$ ( Figure 1).It was found that the most commonly affected and treated teeth were the left permanent maxillary molar with a percentage of $58.1 \%$ and right permanent maxillary molar were about $41.9 \%$ ( Figure 2). It was found the female distribution was higher with a percentage of $51.4 \%$ whereas males were about $48.6 \%$ ( Figure 3). The statistical analysis Chi-square test shows p-value (0.069) more than the limit of significance $p<0.05$, a negative correlation between the age of the patients and the pulp therapy procedure as depicted in Figure 4.

Pulpectomy procedures were most commonly performed for immature permanent maxillary molars in this study. According to a study by Raji Viola Solomon et al, 4 out of 5 cases of pulpotomy was successful and coronal pulpotomy was considered an alternative to pulpectomy procedures [16]. In a systematic review by Gunnar Bergenholtz et al,it is stated that it is not possible to determine whether an injured pulp by deep caries can be maintained or whether it should be removed and replaced with a root filling material [17].

George Bogen et al., in his study states that new treatment strategies for direct pulp capping and pulpotomy have shown promising potentials for improved outcomes in immature teeth with extensive caries [18]. Similarly, a study by Jekaterina Gudkind et al,also states vital pulp therapy has been proven to be repeatedly successful and be recommended routinely for pulp exposure of

Figure 1. Shows the frequency distribution of the pulp therapies done among the study population. $\mathrm{X}$ axis corresponds to the pulp therapy procedure and $\mathrm{Y}$ axis corresponds to the number of patients. Pulpectomy (purple bar) was done in 70 patients and pulpotomy (orange bar) was done in 4 patients.

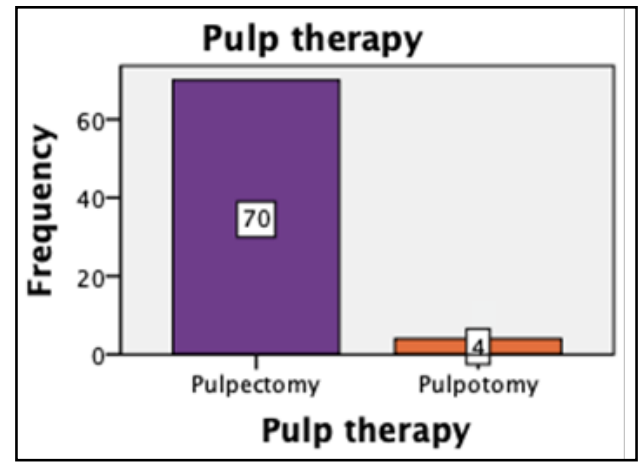


Figure 2. Shows the frequency distribution of the teeth affected among the study population. $\mathrm{X}$ axis corresponds to the tooth affected and $Y$ axis corresponds to the number of patients. It is seen that more number of pulp therapies were done in left maxillary molar (red bar) in 43 cases than right maxillary molar (blue bar) in 31 cases.

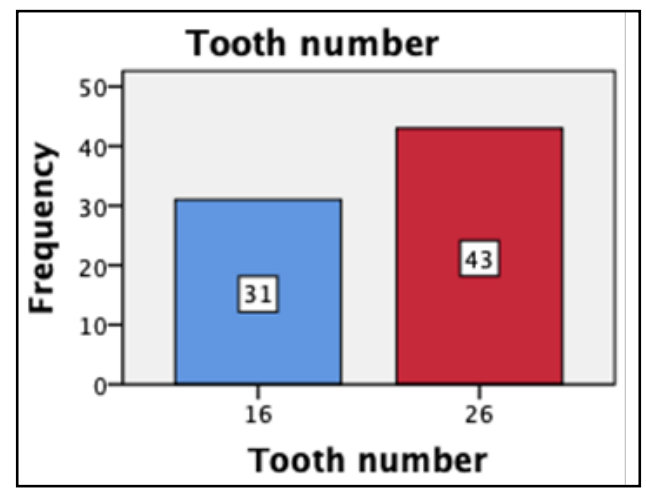

Figure 3. Shows the Gender distribution of the study population. $\mathrm{X}$ axis corresponds to the gender and $\mathrm{Y}$ axis corresponds to the number of patients. Female distribution (green bar) was found to be higher (38 cases) than male distribution (36 cases).

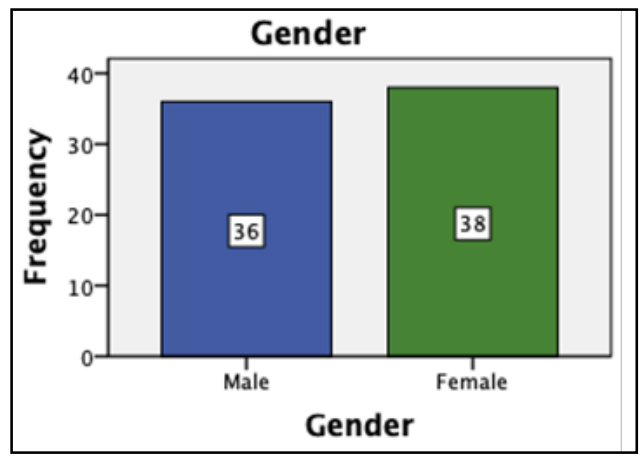

Figure 4. Shows correlation between the pulp therapy procedure and age group of the study population $\mathrm{X}$ axis corresponds to the pulp therapy procedure done and $\mathrm{Y}$ axis corresponds to the age of the patients who have undergone pulp therapy. Pulpectomy was found to be higher among 6 years of age (35.14\%) and pulpotomy among 8 years of age (2.7\%). chi-square test was done and was found to be statistically insignificant [chi square value-8.68 p- 0.069 ( $p>0.05)$ ]. Even though statistically insignificant, majority of the study participants in the age of 6 yrs underwent pulpectomy procedure(blue) than the other age groups.

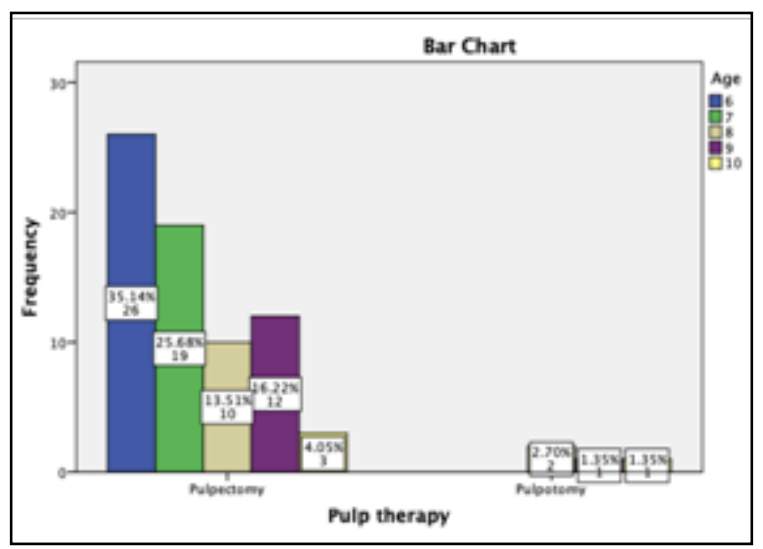

immature permanent teeth [29]. A study by Imad Hassan et al shows that pulpotomy using MTA could be a good alternative for root canal therapy [20]. Considerable research has been conducted in the field of pedodontics with relevance to the current population under study [21-35]. This study helps to identify the prevalence of pulp therapies done in young permanent maxillary molars with Class I caries among the study population. Further studies with a larger population and considering the extent of caries is advised.

\section{Acknowledgement and Declarations}

The authors are thankful to the Director of Saveetha Dental College and Hospitals, Chennai. S.S.Shivanni has contributed in data collection, study design, data analysis, results, tables and manuscript preparation. Dr. Bhagyalakshmi has contributed to manuscript preparation, proof reading of manuscript and reviewing the manuscript. Dr. Balakrishna has contributed to reviewing the manuscript. This study is self funded. There are no conflict of interest. 


\section{Conclusion}

Root formation is not complete in young permanent teeth. Hence, preserving the pulp is necessary to help in the completion of the root ends. Adequate knowledge on the root anatomical variations and absolute awareness of the radiographic limitations, instrumentation procedures, chemical interactions among different endodontic irrigants and root canal filling techniques are essential prior to commencing pulpectomy procedures. Vital pulp therapy can be considered as an alternative to RCT in young permanent molars clinically diagnosed with irreversible pulpitis. In the current study, pulpectomy was highly performed over pulpotomy although many researches state that pulpotomy is preferred for immature permanent teeth. The future scope of this study is to consider the caries extent and to conduct the study among a larger population.

\section{References}

[1]. Mjör IA. Pulp-dentin Biology in Restorative Dentistry. Quintessence Publishing Company.2002: 152.

[2]. Abarajithan M, Velmurugan N, Kandaswamy D. Management of recently traumatized maxillary central incisors by partial pulpotomy using MTA: Case reports with two-year follow-up. J Conserv Dent. 2010 Apr;13(2):1103.Pubmed PMID: 20859487.

[3]. Ahmed HM. Pulpectomy procedures in primary molar teeth. Eur. J. Dent. 2014 Jan 1;3(1):3.

[4]. Eghbal MJ, Asgary S, Baglue RA, Parirokh M, Ghoddusi J. MTA pulpotomy of human permanent molars with irreversible pulpitis. Aust Endod J. 2009 Apr;35(1):4-8.Pubmed PMID: 19335509.

[5]. Asgary S, Ehsani S. Permanent molar pulpotomy with a new endodontic cement: A case series. J Conserv Dent. 2009 Jan;12(1):31-6.Pubmed PMID: 20379438.

[6]. Berk H, Krakow AA. A comparison of the management of pulpal pathosis in deciduous and permanent teeth. Oral Surg Oral Med Oral Pathol. 1972 Dec;34(6):944-55.Pubmed PMID: 4565581.

[7]. Ahmed HM. Anatomical challenges, electronic working length determination and current developments in root canal preparation of primary molar teeth. Int Endod J. 2013 Nov;46(11):1011-22.Pubmed PMID: 23711096.

[8]. Fuks AB. Current concepts in vital primary pulp therapy. Eur J Paediatr Dent. 2002 Sep;3(3):115-20.Pubmed PMID: 12870999.

[9]. Cohenca N, Paranjpe A, Berg J. Vital pulp therapy. Dent Clin North Am. 2013 Jan;57(1):59-73. Pubmed PMID: 23174610.

[10]. Christensen GJ. Pulp Capping. J Am Dent Assoc.1998; 129: 1297-9. Pubmed PMID:9766112.

[11]. Lim KC, Kirk EE. Direct pulp capping: a review. Endod Dent Traumatol. 1987 Oct;3(5):213-9. Pubmed PMID: 3315643.

[12]. Ward J. Vital pulp therapy in cariously exposed permanent teeth and its limitations. Aust Endod J. 2002 Apr;28(1):29-37.Pubmed PMID: 12360679.

[13]. Maltz M, Garcia R, Jardim JJ, de Paula LM, Yamaguti PM, Moura MS, et al. Randomized trial of partial vs. stepwise caries removal: 3-year follow-up. J Dent Res. 2012 Nov;91(11):1026-31. Pubmed PMID: 22983407.

[14]. Wunsch PB. Indirect pulp therapy for young permanent molars. Handbook of Clinical Techniques in Pediatric Dentistry.2015:83-92.

[15]. Bergenholtz G, Axelsson S, Davidson T, Frisk F, Hakeberg M, Kvist T, et al. Treatment of pulps in teeth affected by deep caries - A systematic review of the literature. Singapore Dent J. 2013 Dec;34(1):1-12.Pubmed PMID: 24360260 .

[16]. Naoum H. A Clinical Guide To Endodontics: Peter Carrotte. Aust Endod J. 2004 Aug;30(2):79.
[17]. Solomon RV, Faizuddin U, Karunakar P, Deepthi Sarvani G, Sree Soumya S. Coronal Pulpotomy Technique Analysis as an Alternative to Pulpectomy for Preserving the Tooth Vitality, in the Context of Tissue Regeneration: A Correlated Clinical Study across 4 Adult Permanent Molars. Case Rep Dent. 2015;2015:916060.Pubmed PMID: 26097752.

[18]. Bogen G, Chandler NP. Pulp preservation in immature permanent teeth. Endod Topics. 2010 Sep;23(1):131-52.

[19]. Suhag K, Duhan J, Tewari S, Sangwan P. Success of Direct Pulp Capping Using Mineral Trioxide Aggregate and Calcium Hydroxide in Mature Permanent Molars with Pulps Exposed during Carious Tissue Removal: 1-year Follow-up. J Endod. 2019 Jul;45(7):840-847.Pubmed PMID: 31104819.

[20]. Taha NA, Abdulkhader SZ. Full Pulpotomy with Biodentine in Symptomatic Young Permanent Teeth with Carious Exposure. J Endod. 2018 Jun;44(6):932-937.Pubmed PMID: 29681479.

[21]. Jeevanandan G. Kedo-S Paediatric Rotary Files for Root Canal Preparation in Primary Teeth - Case Report. J Clin Diagn Res. 2017 Mar;11(3):ZR03ZR05.Pubmed PMID: 28511532.

[22]. Lakshmanan L, Mani G, Jeevanandan G, Ravindran V, Ganapathi SE. Assessing the quality of root canal filling and instrumentation time using kedo-s files, reciprocating files and k-files. Brazilian Dental Science. 2020 Jan 31;23(1):7.

[23]. Govindaraju L, Jeevanandan G, Subramanian EMG. Comparison of quality of obturation and instrumentation time using hand files and two rotary file systems in primary molars: A single-blinded randomized controlled trial. Eur J Dent. 2017 Jul-Sep;11(3):376-379.Pubmed PMID: 28932150.

[24]. Govindaraju L, Jeevanandan G, Subramanian EM. Knowledge and practice of rotary instrumentation in primary teeth among Indian dentists: a questionnaire survey. J Int Oral Health. 2017 Mar 1;9(2):45.

[25]. Somasundaram S, Ravi K, Rajapandian K, Gurunathan D. Fluoride Content of Bottled Drinking Water in Chennai, Tamilnadu. J Clin Diagn Res. 2015 Oct;9(10):ZC32-4.Pubmed PMID: 26557612.

[26]. Jeevanandan G, Govindaraju L. Clinical comparison of Kedo-S paediatric rotary files vs manual instrumentation for root canal preparation in primary molars: a double blinded randomised clinical trial. Eur Arch Paediatr Dent. 2018 Aug;19(4):273-278.Pubmed PMID: 30003514.

[27]. Govindaraju L, Jeevanandan G, Subramanian E. Clinical Evaluation of Quality of Obturation and Instrumentation Time using Two Modified Rotary File Systems with Manual Instrumentation in Primary Teeth. J Clin Diagn Res. 2017 Sep;11(9):ZC55-ZC58.Pubmed PMID: 29207834.

[28]. Ravikumar D, Jeevanandan G, Subramanian EM. Evaluation of knowledge among general dentists in treatment of traumatic injuries in primary teeth: A cross-sectional questionnaire study. Eur. J. Dent. 2017 Apr;11(2):232-7.

[29]. Panchal V, Jeevanandan G, Subramanian E. Comparison of instrumentation time and obturation quality between hand K-file, H-files, and rotary Kedo-S in root canal treatment of primary teeth: A randomized controlled trial. J Indian Soc Pedod Prev Dent. 2019 Jan-Mar;37(1):75-79. PMID: 30804311.

[30]. Christabel SL, Gurunathan D. Prevalence of type of frenal attachment and morphology of frenum in children, Chennai, Tamil Nadu. World J Dent. 2015 Oct;6(4):203-7.

[31]. Packiri S, Gurunathan D, Selvarasu K. Management of Paediatric Oral Ranula: A Systematic Review. J Clin Diagn Res. 2017 Sep;11(9):ZE06-ZE09. Pubmed PMID: 29207849; PMCID: PMC5713871.

[32]. Gurunathan D, Shanmugavel AK. Dental neglect among children in Chennai. J Indian Soc Pedod Prev Dent.2016 Oct 1; 34(4):364.

[33]. Govindaraju L, Gurunathan D. Effectiveness of Chewable Tooth Brush in Children-A Prospective Clinical Study. J Clin Diagn Res. 2017 Mar;11(3):ZC31-ZC34.Pubmed PMID: 28511505.

[34]. Subramanyam D, Gurunathan D, Gaayathri R, Vishnu Priya V. Comparative evaluation of salivary malondialdehyde levels as a marker of lipid peroxidation in early childhood caries. Eur J Dent. 2019 Sep1;12(1):67-70. Pubmed PMID: 29657527.

[35]. Ramakrishnan M, Bhurki M. Fluoride, Fluoridated Toothpaste Ef icacy And Its Safety In Children-Review. International Journal of Pharmaceutical Research. 2018 Oct;10(4):109-14. 